\title{
Innovative Method to Produce Large-Area Freestanding Functional Ceramic Foils
}

\section{Glenn J. T. Leighton ${ }^{\mathrm{a}, *}$, Paul M. Jones ${ }^{\mathrm{a}}$, Quentin Lonne ${ }^{\mathrm{a}}$, Robert A. Dorey ${ }^{\mathrm{b}}$, Fabien Giuliano ${ }^{\mathrm{a}}$}

a Surface Engineering \& Nanotechnology Institute (SENTI), Cranfield University, College Road, Cranfield, Bedfordshire, MK43 0AL, UK.

${ }^{b}$ Department of mechanical engineering services, University of Surrey, Guildford, Surrey, GU2 7XH, UK.

*Corresponding author's email address: g.j.t.leighton@cranfield.ac.uk (Glenn J. T. Leighton).

Other authors' email addresses:

p.m.jones@cranfield.ac.uk (Paul M. Jones),

quentin.lonne@cranfield.ac.uk (Quentin Lonne),

r.dorey@surrey.ac.uk (Robert A. Dorey),

fabien.giuliano@cranfield.ac.uk (Fabien Giuliano). 


\begin{abstract}
Using thick and thin films instead of bulk functional materials presents tremendous advantages in the field of flexible electronics and component miniaturization. Here, a low-cost method to grow and release large-area, microscale thickness, freestanding, functional, ceramic foils is reported. It uses evaporation of sodium chloride to silicon wafer substrates as sacrificial layers, upon which functional lead titanate zirconate ceramic films are grown at $710{ }^{\circ} \mathrm{C}$ maximum temperature to validate the method. The freestanding, functional foils are then released by dissolution of the sacrificial sodium chloride in water and have the potential to be integrated into low-thermal stability printed circuits and flexible substrates. The optimization of the sodium chloride layer surface quality and bonding strength with the underlying wafer is achieved thanks to pre-annealing treatment.
\end{abstract}

Keywords: freestanding functional foils, $\mathrm{NaCl}$ sacrificial layers, PZT ceramic films, ferroelectric.

\title{
1. Introduction
}

Functional ceramics with ferroelectric properties have many applications in electronics as transducers, actuators and sensors [1] that can be used for example in mobile phones [2], structural health monitoring [3], medical imaging [4], robotic surgery [5], touch screens [6], micro-positioning [7] and active vibration control [8]. The use of thick and thin films as opposed to bulk functional ceramics has many benefits in terms of cost, size, weight and sensitivity, which greatly enhances the usability of transducers, actuators and sensors [1]. Therefore, having to integrate a bulky substrate, which serves no other purpose than growing the functional film, is an inconvenience for electronic components fabrication and an obstacle to their miniaturisation. And since growing functional ceramics generally requires a minimal temperature around $500^{\circ} \mathrm{C}$, it is preferable to integrate freestanding microscale foils on low-thermal stability printed circuits or polymers for flexible electronics, rather than growing them directly in-situ. Solutions such as thinning bulk functional ceramics [9], removing the growth substrate [10] or transferring the functional ceramic foil to a new carrier substrate [11,12] using 
respectively grinding, etching or a laser process, have been suggested. However, thinning functional bulk materials to less than $30 \mu \mathrm{m}$ is long, tedious and very challenging as they are generally friable ceramics and the process results in subsurface damage [9]. Moreover, procedures to remove the substrate such as isotropic etching are very costly in terms of time and equipment and consumables [10]. Finally, the laser transfer is timeconsuming, limited in feature size and requires expensive transparent growth substrates, generally a glass material with a low coefficient of thermal expansion $\left(\alpha_{\mathrm{CTE}}\right)$. Besides, there is the technical challenge to focus the beam of a very expensive-to-operate laser at the functional ceramic layer/glass growth substrate interface to transfer the functional layer to a new carrier without creating cracks in the ceramic film. Indeed, the high energy density produced by the laser and the difference between the $\alpha_{\mathrm{CTE}}$ of the functional film and the growth substrate, are likely to generate stresses and cause cracks $[11,12]$.

In the past, sodium chloride $(\mathrm{NaCl})$, a non-oxide ceramic, has been used as a cheap, bulk, sacrificial material to achieve freestanding foils of materials such as $\mathrm{Ni}$ [13]. Besides, it was deposited onto a suitable carrier surface using an evaporation technique [14-16]. However, to the best of our knowledge, this work is the first successful attempt to deposit functional ceramic films on evaporated, sacrificial, $\mathrm{NaCl}$ layers and then release them as microscale, freestanding foils thanks to a simple dissolution of the $\mathrm{NaCl}$ interface in water. The chosen functional material was a lead zirconate titanate (PZT) ceramic, developed at Cranfield University and previously studied in literature $[17,18]$, as it is one of the most widely used ferroelectric materials, commonly in the morphotropic phase boundary composition of $\mathrm{Pb}_{1.1}\left(\mathrm{Zr}_{0.52} \mathrm{Ti}_{0.48}\right) \mathrm{O}_{3}[19,20]$.

\section{Experimental section}

\section{A schematic summarizing the whole manufacturing process to obtain $\mathrm{Ti} / \mathrm{Pt} / \mathrm{PZT}$ freestanding foils is presented}

in Fig. 1. First, $\mathrm{NaCl}$ release layers were deposited onto 500- $\mu \mathrm{m}$ thick Si substrates covered with a 300-nm thick top $\mathrm{SiO}_{2}$ layer, using an Edwards thermal evaporator with a tungsten basket heater and an alumina crucible (B8A-3X.030W from Testbourne Ltd, UK). In a typical procedure, the base pressure was maintained at $1 \times 10^{-4}$ $\mathrm{Pa}$ and the current was successively set to $30 \mathrm{~A}$ for $60 \mathrm{~s}, 50 \mathrm{~A}$, and $40 \mathrm{~A}$ for $1250 \mathrm{~s}$ to outgas, melt and deposit 
$250 \mathrm{~nm}$ of $\mathrm{NaCl}$ (Sigma Aldrich $\geq 99.5 \%$ ), respectively. Afterwards, the NaCl-coated substrates were annealed in a Carbolyte box furnace in ambient air at $450,550,650$ or $750{ }^{\circ} \mathrm{C}$, during 1 or 3 hours. Afterwards, a tape test and a dissolution test into $\mathrm{H}_{2} \mathrm{O}$ were carried out to assess the $\mathrm{NaCl} / \mathrm{SiO}_{2}$ bonding strength and the ability to release a functional freestanding foil, respectively. Annealed $\mathrm{NaCl}$ layers were coated with electrodes composed of $8 \mathrm{~nm}$ of Ti and $250 \mathrm{~nm}$ of Pt, using a Nordico radio frequency/direct current (RF/DC) sputter system. Ti and Pt were respectively RF and DC sputtered under argon. Subsequently, 6- $\mu \mathrm{m}$ thick PZT layers were deposited on the surface of the electrodes using a standard composite sol gel methodology described elsewhere [17,18]. Finally, Ti/Pt/PZT foils were released almost instantaneously from the wafers thanks to a simple immersion in $\mathrm{H}_{2} \mathrm{O}$. In some cases, a Nitto Denko - Revalpha $3195 \mathrm{~V}$ tape strip was previously bonded to the surface of the PZT layer. The structure and microstructure, were characterised using X-ray diffraction (XRD, Siemens D5000) and scanning electron microscopy (SEM, Phillips XL30). Moreover, the Na and Cl content in the freestanding foils was determined by energy dispersive spectrometry (EDS, Oxford Instruments). Finally, the capacitance loss and ferroelectric properties were studied with a precision component analyser (Wayne Kerr 6425) and a Radiant Technology RT66C Ferroelectric tester, respectively. For the latter characterisation, the PZT film was either $\mathrm{Si} / \mathrm{SiO}_{2}$ wafer-supported and sandwiched between two Pt electrodes, or freestanding and sandwiched between a Pt electrode and a liquid metal eutectic drop of indium, gallium and tin, commonly referred to as Galinstan [21,22], and brought to the PZT surface with a hypodermic syringe. The samples were stored in a vacuum desiccator between each process and/or characterisation step to avoid absorption of atmospheric moisture.

\section{Results and discussion}

In a preliminary test, a $\mathrm{Pt}$ film was deposited on top of an $\mathrm{NaCl}$ non-oxide ceramic layer without any previous annealing of the latter, which caused the whole coating to delaminate from the $\mathrm{SiO}_{2}$ surface. This meant that the stress generated at the $\mathrm{Pt} / \mathrm{NaCl}$ interface exceeded the binding energy at the $\mathrm{NaCl} / \mathrm{SiO}_{2}$ one. Indeed, since the wafer was held at ambient chamber temperature during the $\mathrm{NaCl}$ deposition, the thermal energy was too low to 
induce a satisfactory $\mathrm{NaCl}$ grain consolidation or a chemical bonding at the $\mathrm{NaCl} / \mathrm{SiO}_{2}$ interface. The influence of the water possibly contained in the hygroscopic $\mathrm{NaCl}$ layer was assumed to be non-significant as it should have been extracted when the chamber was vacuumed down to a pressure of $1.33 \times 10^{-5} \mathrm{~Pa}$ before the Pt sputtering.

Hence, in order to optimise adhesion of $\mathrm{NaCl}$ to $\mathrm{SiO}_{2}$, and its surface quality to grow a PZT ceramic film upon, post evaporation annealing was performed as described in Table 1. The corresponding samples are referenced as "NaCl $T / t$ ", with $T$ the annealing temperature in ${ }^{\circ} \mathrm{C}$ and $t$ the dwell time in hours. Three possible beneficial effects were expected [23-25]: a densification of $\mathrm{NaCl}$ improving the mechanical integrity of this layer, a grain growth lowering the surface roughness and giving a higher quality interface for the Ti/Pt/PZT film deposition, and the formation of a sodium silicate ceramic phase $\left(\mathrm{Na}_{x} \mathrm{Si}_{\mathrm{y}} \mathrm{O}_{z}\right)$ promoting a strong chemical bond at the $\mathrm{NaCl} / \mathrm{SiO}_{2}$ interface.

According to the results summarised in Table 1, the samples annealed at 450 and $550{ }^{\circ} \mathrm{C}$, regardless of the dwell time, were soluble in water but mostly peeled off the $\mathrm{SiO}_{2}$ layer during a tape test, demonstrating weak adhesion. On the contrary, $\mathrm{NaCl} 650 / 3, \mathrm{NaCl} 750 / 1$ and $\mathrm{NaCl} 750 / 3$ remained entirely attached to the substrate during the tape test but were not soluble in water, indicating a very strong chemical bonding. Finally, $\mathrm{NaCl} 650 / 1$ was both soluble in water and unpeeled during the tape test, making it the most likely suitable layer for growing and releasing freestanding Ti/Pt/PZT foils.

The microstructure of $\mathrm{NaCl} 450 / 1$ and $\mathrm{NaCl} 550 / 1$ remained quite similar to the as-deposited $\mathrm{NaCl}$ one (Fig. 2a) but for $\mathrm{NaCl} 450 / 3$ (Fig. 2c) and $\mathrm{NaCl} 550 / 3$ (Fig. 2d), the grains became slightly bigger with rounded angles, more triple junction grain boundaries and fewer intergranular pores. Nonetheless, in both cases, the consolidation due to the densification was not sufficient to prevent the delamination from $\mathrm{SiO}_{2}$ during the tape test. The microstructure of $\mathrm{NaCl}$ 650/1 (Fig. 2b) and $\mathrm{NaCl}$ 650/3 (Fig. 2e) exhibited considerably larger grains with almost no intergranular pores remaining, which indicated a higher densification accompanied by a significant grain growth. Therefore, $\mathrm{NaCl} 650 / 1$ and $\mathrm{NaCl} 650 / 3$ offered a smoother surface, better adapted to the Ti/Pt/PZT foil deposition. There was also a chemical bonding with $\mathrm{SiO}_{2}$ as both samples could resist to 
delamination during the tape test. In the case of $\mathrm{NaCl} 650 / 3$ it was even too strong as it became insoluble in water. Finally, when the annealing temperature was increased up to $750{ }^{\circ} \mathrm{C}$, the morphology was completely modified. $\mathrm{NaCl} 750 / 1$ was composed of very large, smooth grains whereas only a few large grains embedded in a smooth underlying layer could be observed on the surface of $\mathrm{NaCl} 750 / 3$ (Fig. 2f).

The XRD patterns of $\mathrm{NaCl} 650 / 1, \mathrm{NaCl} 650 / 3$ and $\mathrm{NaCl} 750 / 3$, normalised relatively to their respective maximum intensities, are shown on Fig. 3a. The intensity decrease of the $\mathrm{NaCl}$ peaks at 31.76 and $45.52^{\circ}$ between $\mathrm{NaCl} 650 / 1$ and $\mathrm{NaCl} 650 / 3$ indicates that $650{ }^{\circ} \mathrm{C}$ was a temperature high enough to initiate a significant chemical bonding thanks to $\mathrm{Na}$ diffusion inside $\mathrm{SiO}_{2}$. However, no sodium silicate phase was detected by XRD, which means that its crystallinity and/or quantity were too low. After a 3-hour annealing treatment at $750{ }^{\circ} \mathrm{C}$, the $\mathrm{NaCl}$ phase could not be detected by XRD anymore but peaks corresponding the phases $\mathrm{Na}_{2} \mathrm{Si}_{2} \mathrm{O}_{5}, \mathrm{SiO}_{2}$ and $\mathrm{Na}_{4} \mathrm{SiO}_{4}$ appeared at $14.88,21.84$ and $23.12^{\circ}$, respectively. Hence, either all the $\mathrm{NaCl}$ reacted or there was not enough left to be detected by XRD. Moreover, as no XRD peak corresponded to a Clcontaining phase, a chlorinated species gas phase very likely accompanied the $\mathrm{Na}$ diffusion. The co-existence of the phases $\mathrm{Na}_{2} \mathrm{Si}_{2} \mathrm{O}_{5}$ and $\mathrm{Na}_{4} \mathrm{SiO}_{4}$, situated respectively in the left, $\mathrm{Na}_{2} \mathrm{O}$-rich and the right, $\mathrm{SiO}_{2}$-rich parts of the $\mathrm{Na}_{2} \mathrm{O}-\mathrm{SiO}_{2}$ phase diagram [23] (Supporting Information, Fig. S1), could mean that a Na concentration gradient exists through the newly formed sodium silicate layer. In this case, the Na concentration would be lower in the deeper part of the ceramic layer, leading to the formation of the crystalline phases $\mathrm{Na}_{2} \mathrm{Si}_{2} \mathrm{O}_{5}$ and $\mathrm{SiO}_{2}$ (quartz), and higher in the outer part, leading to the formation of $\mathrm{Na}_{4} \mathrm{SiO}_{4}$. Another explanation would be an inhomogeneous $\mathrm{Na}$ diffusion in $\mathrm{SiO}_{2}$ leading to different $\mathrm{Na}_{2} \mathrm{O}-\mathrm{SiO}_{2}$ ratios and hence phases. A sodium silicate phase with an intermediate composition such as $\mathrm{Na}_{2} \mathrm{SiO}_{3}$ might also exist but in a proportion too low to be detected by XRD. In any case, the chemical bonding created by the $\mathrm{Na}$ diffusion inside $\mathrm{SiO}_{2}$ explains why the layers annealed at 650 and $750{ }^{\circ} \mathrm{C}$ were not peeled during the tape test. Furthermore, the insolubility of $\mathrm{NaCl} 650 / 3, \mathrm{NaCl} 750 / 1$ and $\mathrm{NaCl} 750 / 3$ suggests the presence of water-insoluble $\mathrm{SiO}_{2}$ enveloping the watersoluble sodium silicates. Because of the good compromise between its strong bonding with $\mathrm{SiO}_{2}$ and its ability to be dissolved into water to release a freestanding foil, $\mathrm{NaCl} 650 / 1$ was defined as the optimal release layer. An EDS analysis was carried out on both sides of a Ti/Pt/PZT foil released from such a sacrificial layer (Fig. 3b). 
Neither $\mathrm{Na}$, nor $\mathrm{Cl}$ could be detected on the PZT surface, within the detection limit of the EDS apparatus (ca. $0.1 \mathrm{wt} \%$ ). As for the surface of the Ti layer, which was in direct contact with the sacrificial layer, no Na and only $0.1 \mathrm{wt} \%$ of $\mathrm{Cl}$ were found. This means that the sacrificial layer was practically completely dissolved so no significant remaining amount could be identified. Being able to fully dissolve the sacrificial layer is very important because residues of non-conductive $\mathrm{NaCl}$ or sodium silicates on the surface of the functional foil would create a contact resistance, proportional to the amount of those insulating species.

Fig. 4a shows a Ti/Pt/PZT foil being released from a Si wafer into water as the $\mathrm{NaCl}$ layer is being dissolved. Since the totality of the $\mathrm{NaCl}$ release layer was not dissolved exactly at the same time, high stress areas occurred at the interface between the already released and the still bonded parts, thus initiating cracks. Then, given the brittle nature of the PZT ceramic and the high probability of minor defects inside this layer, the cracks could easily propagate throughout the foil. To overcome this problem, a thermal tape strip (Revalpha by Nitto) was bonded to the surface of the PZT layer before its release into water. This not only improved the foil overall mechanical integrity but also limited the angle of curvature at the high-stress released/attached foil interface. With this method, it was possible to release whole, crack-free, $\mathrm{Ti} / \mathrm{Pt} / \mathrm{PZT}$ films in one piece from $\mathrm{She}_{2}$ surface, as shown in Fig. 4b. The tape-supported foils can also be transferred to another substrate, and the tape finally removed from the PZT surface with a low temperature thermal cycle. The polished cross-section micrographs of a freestanding and a classical $\mathrm{Si} / \mathrm{SiO}_{2}$ wafer-supported Ti/Pt/PZT foil can be observed in Fig. 4c and $4 \mathrm{~d}$, respectively. Both of them were $c a .6-\mu \mathrm{m}$ thick and exhibited a similar microstructure, with a compact stacking of grains, very few intergranular pores (large holes were due to grain removal during polishing) and no internal cracks. Fig. $4 \mathrm{c}$ also shows that there is an outstanding conformity between the bottom, dark PZT ceramic layer and the top, bright Ti/Pt metal electrode. Besides, the XRD pattern of a Si $/ \mathrm{SiO}_{2} / \mathrm{NaCl}$-supported Ti/Pt/PZT foil, presented in Fig. 3a, confirms that PZT is the main phase constituting the functional film, with only minor traces of a $\mathrm{ZrO}_{2}$ secondary phase. Firstly, this pattern proves that the structure of a Ti/Pt/PZT film is the same, whether grown directly on a $\mathrm{Si} / \mathrm{SiO}_{2}$ wafer or on an intermediate $\mathrm{NaCl}$ sacrificial layer. In the case of the latter, the higher intensity of the peaks corresponding to $\mathrm{ZrO}_{2}$, and the lower intensity of the peak corresponding to $\mathrm{Pt}$, are simply due to a thicker PZT layer. Secondly, the presence of $\mathrm{ZrO}_{2}$ highlights the need 
of an optimised PZT sintering process (time, temperature) to avoid the presence of this electrically insulating, oxide ceramic, which is expected to lower the overall conductivity of the $\mathrm{PZT}$ foil. $\mathrm{As} \mathrm{ZrO}_{2}$ is formed during the sintering of PZT, it is supposed to be homogeneously distributed through the PZT layer, and hence, the electrical resistivity of the $\mathrm{ZrO}_{2}$-containing PZT is likely to be proportional to the $\mathrm{ZrO}_{2}$ content. As for the weak-intensity XRD peak around $45.52^{\circ}$, corresponding to the phase $\mathrm{NaCl}$, it is due to the sacrificial layer sandwiched between the PZT film and the $\mathrm{Si} / \mathrm{SiO}_{2}$ wafer.

Electrical measurements were performed on both $\mathrm{Si} / \mathrm{SiO}_{2}$ wafer-supported and freestanding PZT films. In the first case, the PZT layer was sandwiched between two similar Pt electrodes. In the second case, the freestanding Ti/Pt/PZT foil was in contact with a liquid drop of Galinstan [21,22], which circular contact area with PZT constituted the top electrode, as seen in Fig. 5a. The obtained electric field vs. polarization curves are plotted on Fig. $5 \mathrm{~b}$ and represent a symmetrical hysteresis loop for the wafer-supported PZT film and an asymmetrical one for the freestanding PZT foil. In the first case, the hysteresis loop symmetry is explained by the fact that the PZT layer is situated between two similar Pt electrodes, thus creating conduction and valance band bendings of the same magnitude in the space charge regions (SCRs) at both PZT/electrode interfaces [26,27]. In the second case, the difference between the Pt and the Galinstan electrodes causes a difference in the band bending magnitude on either side of the PZT film and thus a difference in the length of the SCR into the PZT bulk, which leads to an asymmetrical hysteresis loop. It is also possible that the level of band bending at the Galinstan/PZT interface is not consistent in both orientations when the domain is switched, which also causes an asymmetry in the curve. The freestanding PZT foil had a dielectric constant of 461 at $1 \mathrm{kHz}$ and a higher remnant polarisation than that of the constrained film.

\section{Conclusion}

In summary, PZT functional ceramic films were successfully synthesised on $\mathrm{Si} / \mathrm{SiO}_{2}$ wafer-supported $\mathrm{NaCl}$ sacrificial layers and released as $c a$. 6- $\mu \mathrm{m}$ thick freestanding foils by a simple dissolution of the $\mathrm{NaCl}$ layer in water. An annealing of the $\mathrm{NaCl}$ non-oxide ceramic prior to the PZT films growth was necessary to avoid 
delamination from the wafer during this process. The influence of the temperature and dwell time on $\mathrm{NaCl}$ microstructure and interaction with $\mathrm{SiO}_{2}$ was carefully studied. The annealing parameters offering the best compromise between the sacrificial layer dissolution and its bonding strength to the $\mathrm{SiO}_{2}$ layer were $650{ }^{\circ} \mathrm{C}$ during $1 \mathrm{~h}$ and no significant amount of residual $\mathrm{NaCl}$ was found on the surface of the freestanding foils after their release. The $\mathrm{Ti} / \mathrm{Pt} / \mathrm{PZT}$ foil grown on the $\mathrm{NaCl}$ sacrificial layer had a crystallographic structure and a microstructure very close to those of a $\mathrm{Ti} / \mathrm{Pt} / \mathrm{PZT}$ film grown directly on a $\mathrm{Si} / \mathrm{SiO}_{2}$ wafer. Moreover, the ferroelectric properties of the freestanding Ti/Pt/PZT foil were slightly higher than those of a classically grown, wafer-supported Ti/Pt/PZT film, as evidenced by the higher remnant polarization of the freestanding foil. Due to the good thermal stability of $\mathrm{NaCl}\left(T_{\mathrm{f}}=801^{\circ} \mathrm{C}\right)$, the method presented here could be generalised to a wide variety of freestanding functional foils and find numerous applications in electronics, particularly when components miniaturisation or flexible substrates are required. 


\section{Figure captions}

Fig. 1. Schematic of the manufacturing process of the Ti/Pt/PZT freestanding foils.

Fig. 2. SEM top-views of a) as-deposited $\mathrm{NaCl}$, b) $\mathrm{NaCl} 650 / 1$, c) $\mathrm{NaCl} 450 / 3$, d) $\mathrm{NaCl} 550 / 3$, e) $\mathrm{NaCl} 650 / 3$ and f) $\mathrm{NaCl} 750 / 3$.

Fig. 3. a) XRD patterns of $\mathrm{NaCl} 650 / 1, \mathrm{NaCl} 650 / 3, \mathrm{NaCl} 750 / 3$, a Ti/Pt/PZT film classically grown directly on a $\mathrm{Si} / \mathrm{SiO}_{2}$ wafer, and a $\mathrm{Ti} / \mathrm{Pt} / \mathrm{PZT}$ foil grown on a wafer-supported, $\mathrm{NaCl}$ sacrificial layer; b) EDS spectra carried out on both sides of a Ti/Pt/PZT freestanding foil.

Fig. 4. Optical images of a) a freestanding PZT foil being released in water as the $\mathrm{NaCl}$ layer is being dissolved and b) a tape-bonded, released PZT foil; and SEM polished cross-sections of c) a freestanding PZT foil and d) a $\mathrm{Si} / \mathrm{SiO}_{2}$-supported PZT film.

Fig. 5. a) Optical image of the measurement for the ferroelectric characterisation of the PZT freestanding foil and b) electric field vs. polarization curves for a wafer-supported PZT film and a freestanding PZT foil.

\section{Table caption}

Table 1. Annealed $\mathrm{NaCl}$ samples ID, annealing temperature and time, and dissolution and tape test results. 


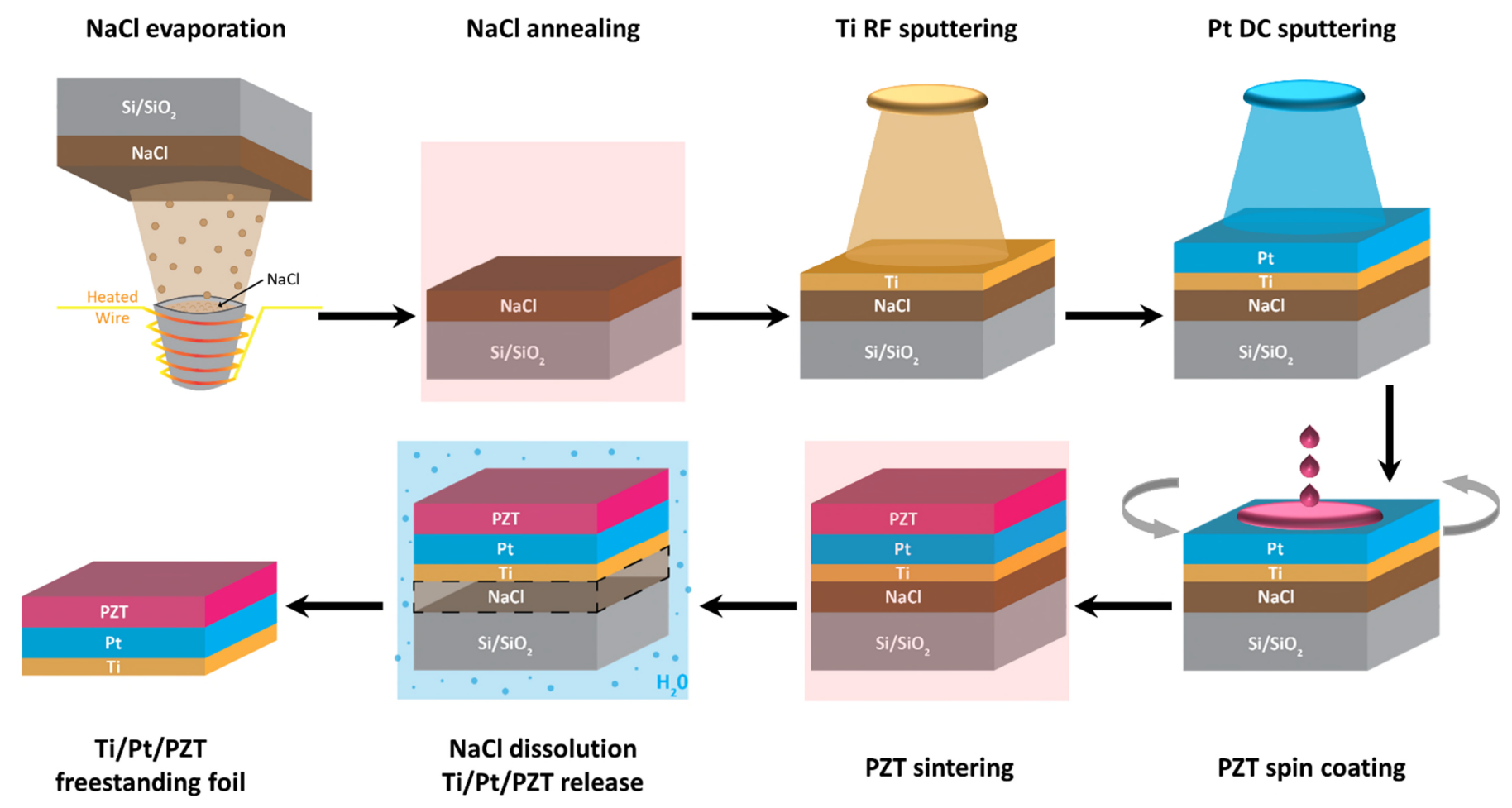

Fig. 1. Schematic of the manufacturing process of the Ti/Pt/PZT freestanding foils. 


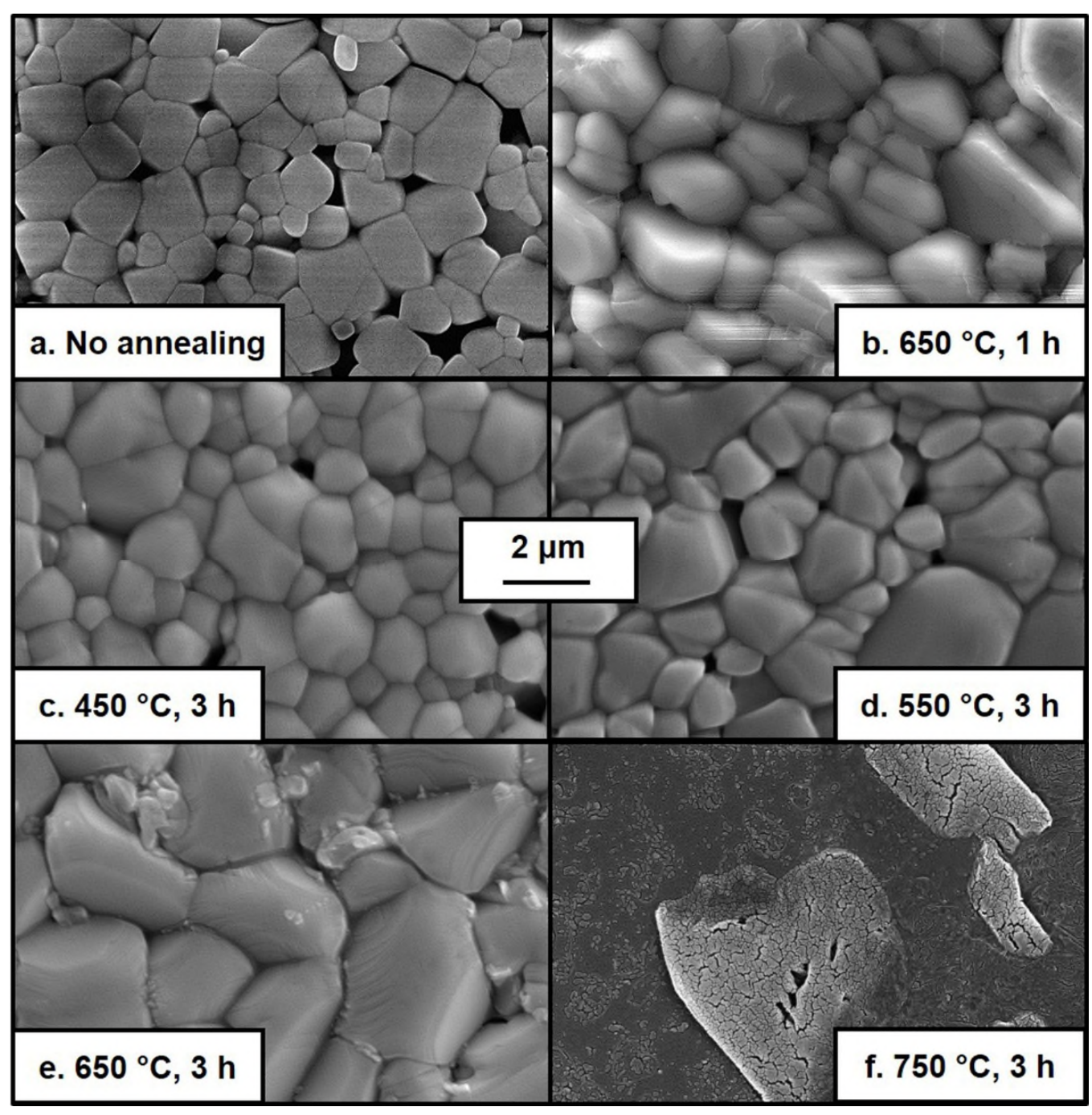

Fig. 2. SEM top-views of a) as-deposited $\mathrm{NaCl}$, b) $\mathrm{NaCl} 650 / 1$, c) $\mathrm{NaCl} 450 / 3$, d) $\mathrm{NaCl} 550 / 3$, e) $\mathrm{NaCl} 650 / 3$ and f) $\mathrm{NaCl} 750 / 3$. 

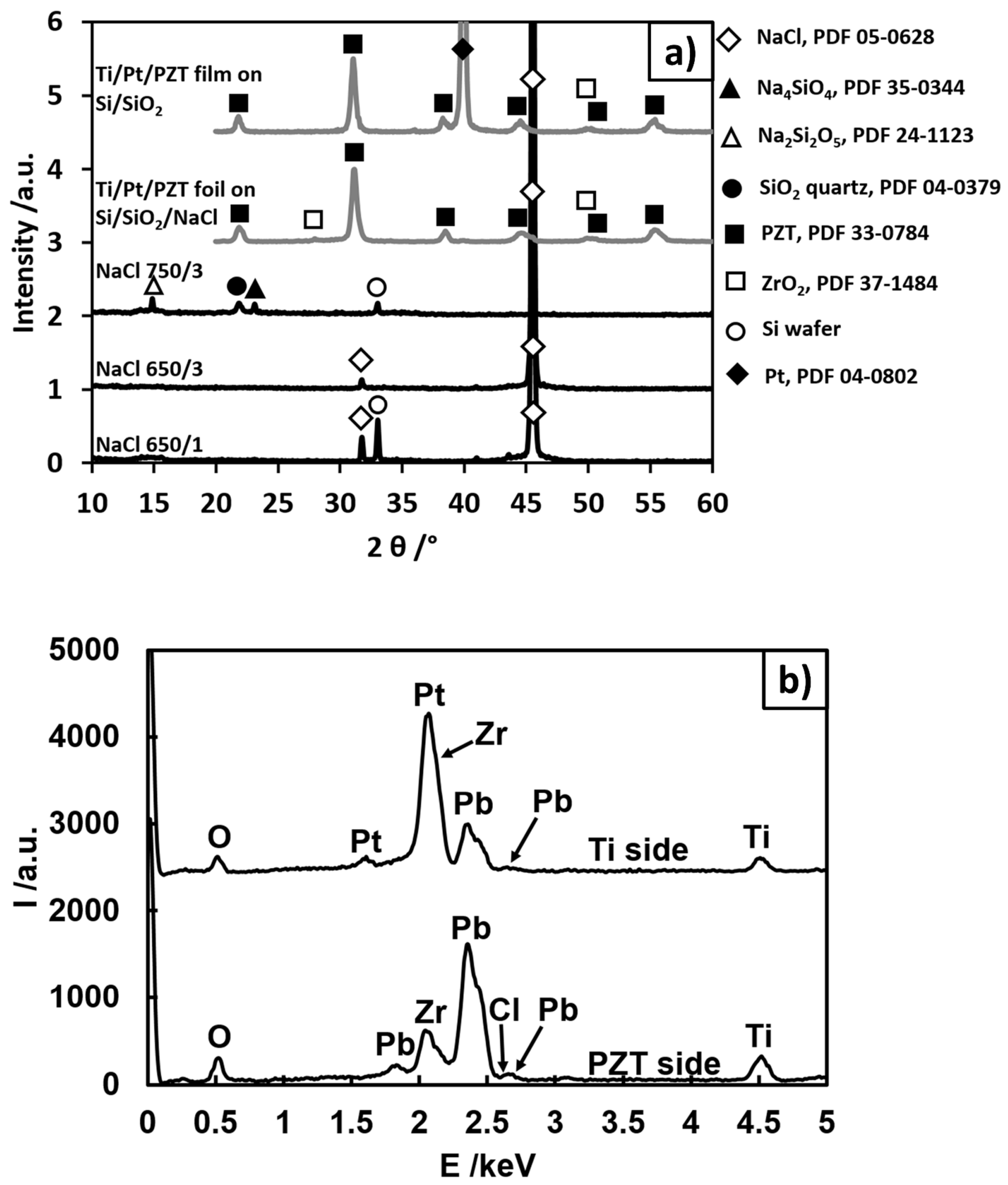

Fig. 3. a) XRD patterns of $\mathrm{NaCl} 650 / 1, \mathrm{NaCl} 650 / 3, \mathrm{NaCl} 750 / 3$, a Ti/Pt/PZT film classically grown directly on a $\mathrm{Si} / \mathrm{SiO}_{2}$ wafer, and a $\mathrm{Ti} / \mathrm{Pt} / \mathrm{PZT}$ foil grown on a wafer-supported, $\mathrm{NaCl}$ sacrificial layer; b) EDS spectra carried out on both sides of a Ti/Pt/PZT freestanding foil. 


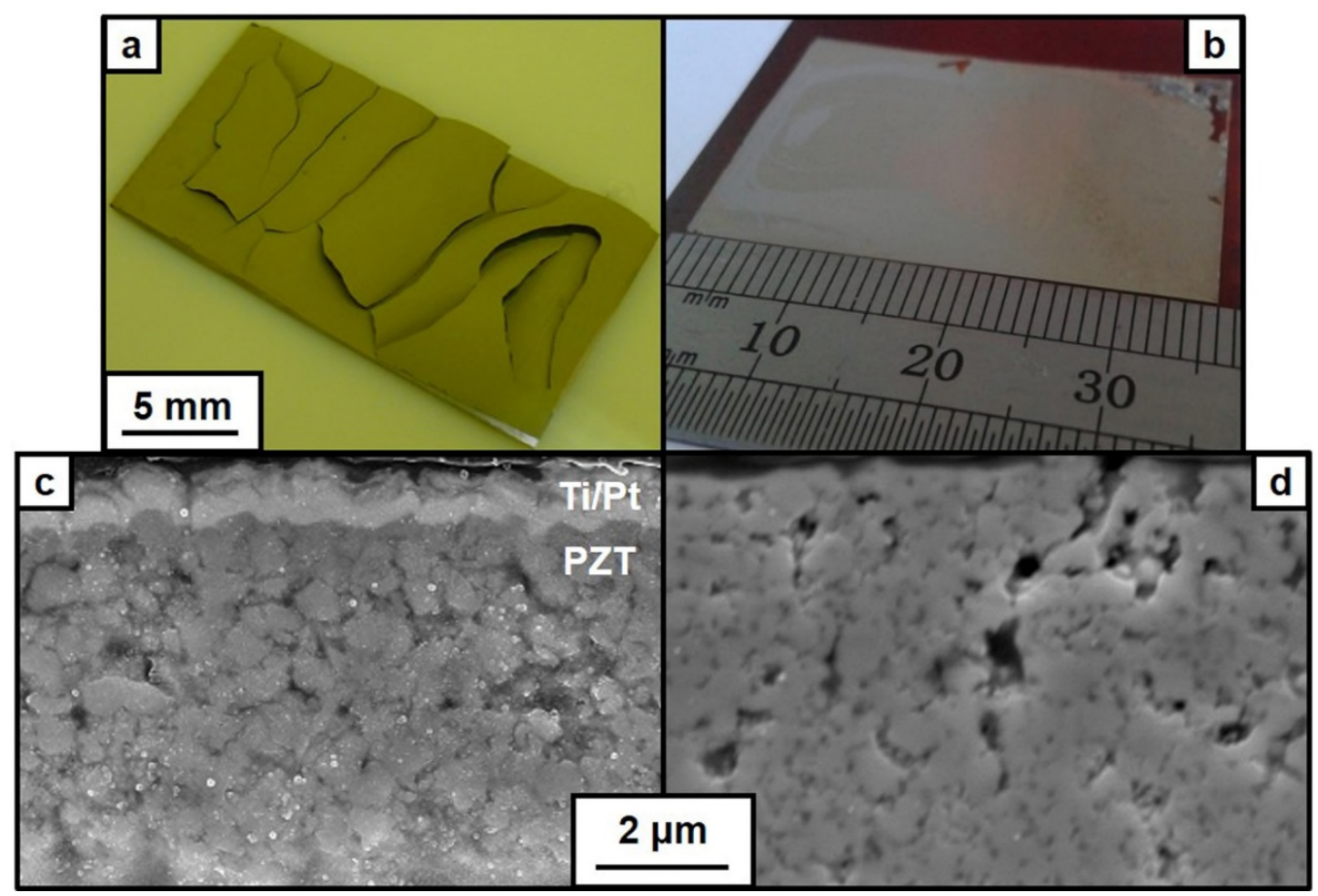

Fig. 4. Optical images of a) a freestanding PZT foil being released in water as the $\mathrm{NaCl}$ layer is being dissolved and b) a tape-bonded, released PZT foil; and SEM polished cross-sections of c) a freestanding PZT foil and d) a $\mathrm{Si} / \mathrm{SiO}_{2}$-supported PZT film. 

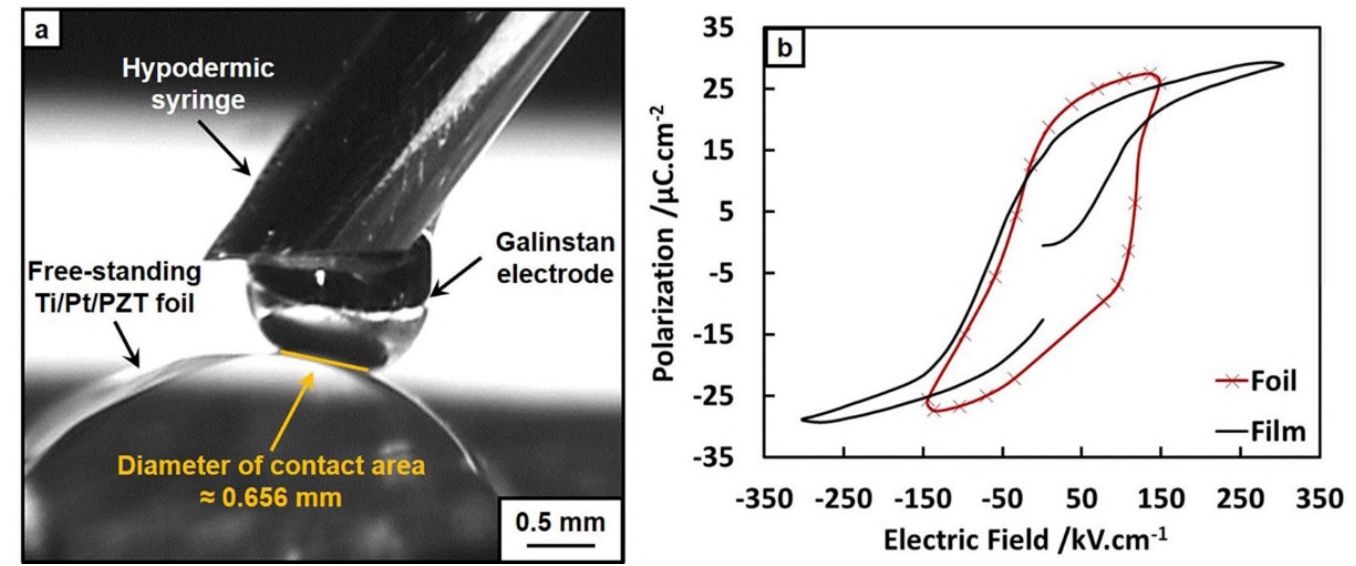

Fig. 5. a) Optical image of the measurement for the ferroelectric characterisation of the PZT freestanding foil and b) electric field vs. polarization curves for a wafer-supported PZT film and a freestanding PZT foil. 
Table 1.

Annealed $\mathrm{NaCl}$ samples ID, annealing temperature and time, and dissolution and tape test results.

\begin{tabular}{ccccc}
\hline Sample ID & $\mathrm{T} /{ }^{\circ} \mathrm{C}$ & $\mathrm{t} / \mathrm{h}$ & Dissolution into $\mathrm{H}_{2} \mathrm{O}$ & Peeling during tape test \\
\hline $\mathrm{NaCl} 450 / 1$ & 450 & 1 & Yes & Yes \\
$\mathrm{NaCl} 450 / 3$ & 450 & 3 & Yes & Yes \\
$\mathrm{NaCl} 550 / 1$ & 550 & 1 & Yes & Yes \\
$\mathrm{NaCl} 550 / 3$ & 550 & 3 & Yes & Yes \\
$\mathrm{NaCl} 650 / 1$ & 650 & 1 & Yes & No \\
$\mathrm{NaCl} 650 / 3$ & 650 & 3 & No & No \\
$\mathrm{NaCl} 750 / 1$ & 750 & 1 & No & No \\
$\mathrm{NaCl} 750 / 3$ & 750 & 3 & No & No \\
\hline
\end{tabular}




\section{Appendix A. Supplementary data}

Supplementary data associated with this article can be found in the online version.

\section{Conflict of interest}

The authors declare no competing and/or financial interest.

\section{Acknowledgments}

The Authors would like to acknowledge the financial support from the EPSRC grant 'Bridging Applied Nano-

Technologists' number EP/G069913/1, under which this work was carried out.

\section{References}

[1] S.A. Wilson, R.P.J. Jourdain, Q. Zhang, R.A. Dorey, C.R. Bowen, M. Willander, Q.U. Wahab, M. Willander, S.M. Al-hilli, O. Nur, E. Quandt, C. Johansson, E. Pagounis, M. Kohl, J. Matovic, B. Samel, W. van der Wijngaart, E.W.H. Jager, D. Carlsson, Z. Djinovic, M. Wegener, C. Moldovan, R. Iosub, E. Abad, M. Wendlandt, C. Rusu, K. Persson, New materials for micro-scale sensors and actuators: An engineering review, Mater. Sci. Eng. R Rep. 56 (2007) 1-129. doi:10.1016/j.mser.2007.03.001.

[2] R. Aigner, MEMS in RF Filter Applications: Thin-film Bulk Acoustic Wave Technology, Sens. Update. 12 (2003) 175-210. doi:10.1002/seup.200390006.

[3] A.J. Pickwell, R.A. Dorey, D. Mba, Thick film, acoustic emission sensors for embedded structural health monitoring systems, in: S. Okumura, T. Kawai, P. Chen, R.B.K.N Rao, Nara, Japan, 2010: pp. 677-684. https://dspace.lib.cranfield.ac.uk/handle/1826/7261 (accessed May 11, 2017).

[4] P. Marechal, F. Levassort, J. Holc, L.P. Tran-Huu-Hue, M. Kosec, M. Lethiecq, High-frequency transducers based on integrated piezoelectric thick films for medical imaging, IEEE Trans. Ultrason. Ferroelectr. Freq. Control. 53 (2006) 1524-1533. doi:10.1109/TUFFC.2006.1665110.

[5] J. Lee, W. Choi, Y.K. Yoo, K.S. Hwang, S.-M. Lee, S. Kang, J. Kim, J.H. Lee, A Micro-Fabricated Force Sensor Using an All Thin Film Piezoelectric Active Sensor, Sensors. 14 (2014) 22199-22207. doi:10.3390/s141222199.

[6] S.J. Dempsey, M. Szablewski, D. Atkinson, Tactile sensing in human-computer interfaces: The inclusion of pressure sensitivity as a third dimension of user input, Sens. Actuators Phys. 232 (2015) 229-250. doi:10.1016/j.sna.2015.05.025.

[7] J. Juuti, M. Leinonen, H. Jantunen, Micropositioning, in: A. Safari, E.K. Akdoğan (Eds.), Piezoelectric Acoust. Mater. Transducer Appl., Springer US, 2008: pp. 319-340. doi:10.1007/978-0-387-76540-2_16.

[8] D.F.L. Jenkins, M.J. Cunningham, G. Velu, D. Remiens, The use of sputtered ZnO piezoelectric thin films as broad-band microactuators, Sens. Actuators Phys. 63 (1997) 135-139. doi:10.1016/S09244247(97)01520-3. 
[9] S. Arai, S.A. Wilson, J. Corbett, R.W. Whatmore, Ultra-precision grinding of PZT ceramics-Surface integrity control and tooling design, Int. J. Mach. Tools Manuf. 49 (2009) 998-1007. doi:10.1016/j.ijmachtools.2009.05.013.

[10] R. Guerre, U. Drechsler, D. Bhattacharyya, P. Rantakari, R. Stutz, R.V. Wright, Z.D. Milosavljevic, T. Vaha-Heikkila, P.B. Kirby, M. Despont, Wafer-Level Transfer Technologies for PZT-Based RF MEMS Switches, J. Microelectromechanical Syst. 19 (2010) 548-560. doi:10.1109/JMEMS.2010.2047005.

[11] C. James, T. Chakraborty, A. Brown, T. Comyn, R. Dorey, J. Harrington, A.J. Laister, R.E. Miles, C. Puchmark, B. Xu, W. Xiong, Q. Zhang, S.J. Milne, Laser transfer processing for the integration of thin and thick film ferroelectrics, J. Mater. Sci. 44 (2009) 5325-5331. doi:10.1007/s10853-009-3609-2.

[12] A. Bansal, R. Hergert, G. Dou, R.V. Wright, D. Bhattacharyya, P.B. Kirby, E.M. Yeatman, A.S. Holmes, Laser transfer of sol-gel ferroelectric thin films using an ITO release layer, Microelectron. Eng. 88 (2011) 145-149. doi:10.1016/j.mee.2010.09.021.

[13] F. Gao, R. Zheng, G. Cheng, T. Yang, Influence of substrates on roughness of self-supporting Ni films, Nucl. Instrum. Methods Phys. Res. Sect. Accel. Spectrometers Detect. Assoc. Equip. 577 (2007) 397-401. doi:10.1016/j.nima.2007.03.033.

[14] H. Bethge, K.W. Keller, Evaporation rate of $\mathrm{NaCl}$ in a vacuum, J. Cryst. Growth. 23 (1974) 105-112. doi:10.1016/0022-0248(74)90109-2.

[15] K.W. Keller, Modes of crystal growth revealed by electron microscopy on NaCl, J. Cryst. Growth. 74 (1986) 161-171. doi:10.1016/0022-0248(86)90260-5.

[16] C. Tegenkamp, W. Ernst, M. Eichmann, H. Pfnür, Stepped $\mathrm{NaCl}$ films grown epitaxially on Si-precovered vicinal Ge(100), Surf. Sci. 466 (2000) 41-53. doi:10.1016/S0039-6028(00)00716-0.

[17] R.A. Dorey, F.F.C. Duval, R.D. Haigh, R.W. Whatmore, The Effect of Repeated Sol Infiltrations on the Microstructure and Electrical Properties of PZT Composite Sol-Gel Films, Ferroelectrics. 267 (2002) 373 378. doi:10.1080/00150190211009.

[18] R.A. Dorey, R.W. Whatmore, S.P. Beeby, R.N. Torah, N.M. White, Screen Printed PZT Composite Thick Films, Integr. Ferroelectr. 63 (2004) 89-92. doi:10.1080/10584580490458766.

[19] R. Guo, L.E. Cross, S.-E. Park, B. Noheda, D.E. Cox, G. Shirane, Origin of the High Piezoelectric Response in PbZr1-xTixO3, Phys. Rev. Lett. 84 (2000) 5423-5426. doi:10.1103/PhysRevLett.84.5423.

[20] S. Zhang, R. Xia, T.R. Shrout, Lead-free piezoelectric ceramics vs. PZT?, J. Electroceramics. 19 (2007) 251-257. doi:10.1007/s10832-007-9056-Z.

[21] P. Surmann, H. Zeyat, Voltammetric analysis using a self-renewable non-mercury electrode, Anal. Bioanal. Chem. 383 (2005) 1009-1013. doi:10.1007/s00216-005-0069-7.

[22] P. Surmann, H. Channaa, Anodic Stripping Voltammetry with Galinstan as Working Electrode, Electroanalysis. 27 (2015) 1726-1732. doi:10.1002/elan.201400752.

[23] F.C. Kracek, The System Sodium Oxide-Silica, J. Phys. Chem. 34 (1929) 1583-1598. doi:10.1021/j150313a018.

[24] D. Knoppik, H.-C. Bartscherer, $\{110\}$ Surface structure and degree of coarsening of $\mathrm{NaCl}$ crystals annealed near the thermodynamic equilibrium of crystal and vapour, J. Cryst. Growth. 36 (1976) 342-344. doi:10.1016/0022-0248(76)90297-9.

[25] E.A. Olevsky, V. Tikare, T. Garino, Multi-Scale Study of Sintering: A Review, J. Am. Ceram. Soc. 89 (2006) 1914-1922. doi:10.1111/j.1551-2916.2006.01054.x.

[26] S. Wu, Polarization reversal and film structure in ferroelectric Bi4Ti3O12 films deposited on silicon, J. Appl. Phys. 50 (1979) 4314-4318. doi:10.1063/1.326415.

[27] J.F. Scott, C.A. Araujo, B.M. Melnick, L.D. McMillan, R. Zuleeg, Quantitative measurement of spacecharge effects in lead zirconate-titanate memories, J. Appl. Phys. 70 (1991) 382-388. doi:10.1063/1.350286. 
2018-03-31

\title{
Innovative method to produce large-area freestanding functional ceramic foils
}

\author{
Leighton, Glenn J. T.
}

Elsevier

Glenn J.T. Leighton, Paul M. Jones, Quentin Lonne, et al., (2018) Innovative method to produce large-area freestanding functional ceramic foils, Journal of the European Ceramic Society, Volume 38, Issue 10, August 2018, pp. 3483-3488

https://doi.org/10.1016/j.jeurceramsoc.2018.03.051

Downloaded from Cranfield Library Services E-Repository 